\title{
A STUDY OF HISTORICAL PRESERVATION LEARNING BASED ON COGNITIVE DEVELOPMENT THEORY
}

\author{
Kuo-Hua Wenga ${ }^{\mathrm{a}}$, Ya-Ning Yen ${ }^{\mathrm{b}, *}$, Yun-Wu Wu \\ a Dept. of Interior Design, University of China Technology, No. 56, Sec. 3, Xinglong Rd., Wunshan District, Taipei City 116, \\ Taiwan (R.O.C.) - ghwong@ cute.edu.tw \\ ${ }^{b}$ Dept. of Architecture, University of China Technology, No. 56, Sec. 3, Xinglong Rd., Wunshan District, Taipei City 116, Taiwan \\ (R.O.C.) - (alexyen, davidwu)@ cute.edu.tw, *Corresponding Author
}

KEY WORDS: Cognitive development, Content analysis, Cultural heritage, Latent Semantic Analysis

\begin{abstract}
:
The study is to explore how the youth forum activities help the participants establish their concept of property conservation and cognitive development by means of scaffolding instruction. First, the research begins by raising the issues of asset preservation with the establishment of the concept of field; the issues are the content of the scaffolding learning forum. Second, this study uses content analysis to explore the cognitive development and learning performance of the participants during the interactive process. The results show that interactive learning activities can effectively promote all the participants' cognitive development, on which different backgrounds have little influence. The participants' cognitive development is mostly concentrated in the application and analysis phase. The results can be used as a reference for future research.
\end{abstract}

\section{MOTIVATION}

\subsection{Goal}

"Quebec Declaration-ON THE PRESERVATION OF THE SPIRIT OF PLACE" was announced on the 16th annual meeting of International Council on Monuments and Sites (ICOMOS). The declaration pointed out: 1. Re-thinking the spirit of place, 2. The threats to the spirit of place, 3. Safeguarding the spirit of place, 4. Transmitting the spirit of place. The $4^{\text {th }}$ point-transmitting the spirit of place- pointed out that interaction and communication with stakeholders is the key to success in guarding, using, and consolidating the spirit of place. Understanding the spirit of place, cultural communities of local tradition play important roles as promoters to launch formal or informal conservation activities to assure the development of the community and society . "Quebec Declaration" also encouraged younger generation to get deeply and widely involved in policy-making and the management of the spirit of place. In the $17^{\text {th }}$ ICOMOS annual meeting, the "Paris Declaration" was announced, which pointed out that with professional training, stakeholders will be able to keep their ownership in the process of development by raising their awareness of heritage conservation. Both annual meetings put a lot of emphasis on the participation of younger generation and stakeholders.

Since 2009, Bureau of Cultural Heritage, which is now Ministry of Culture, started to hold cultural forums for younger generation in order to encourage students of related majors to get involved in the conservation project in Taiwan. The main goals of this forum were to help students build their own schema of cultural heritage conservation through formal and informal interactions and scaffolding learning. This forum not only had some lecture courses and field survey, but also looked into the policy of cultural heritage conservation and how we can meet the trend of conservation around the world. The main purpose of holding forums for the youth is to inspire various ideas from younger generation and make them care more about cultural heritage conservation of by participating in this forum.
This paper explores the cognitive development and learning performance of students of different backgrounds after their participation in this forum.

First, this study analyzes the importance of cultural heritage through literature review. Second, this study uses content analysis and LSA to analyze the learning performance of students of different backgrounds after the youth forum.

\section{LITERATURE REVIEW}

\subsection{Heritage Conservation}

From "Quebec Declaration", we can understand that the approach to and object of conservation have been extended from a single building to a whole district conservation. The conservation work focuses on both tangible and intangible heritage as well as echoing the world trend of global sustainable development. In the process of developing the spirit of place, authenticity of living has been reserved. Therefore, to respect the spirit of place, we should rethink how to use the new approach to interpret the former accepted spirit of place, instead of plagiarizing or following the old and traditional approach to save the value of tangible and intangible assets for long(Norberg-Schulz, 1980/2002).

In consideration of the environment around the cultural heritage site, different terms are used to refer to a place: "Xi'an Declaration" uses "setting", "Quebec Declaration" uses "place", and "Burra Charter," uses "site". Although three declarations use different terms, all the declarations emphasize that structure and environment cannot be discussed separately because they have a close relationship both in essence and spirit.

"Burra Charter" places emphasis on features of places and evaluate a place with Outstanding Universal Value (OUV) standard, which has got rid of the past rigid way. There are four active meanings in "Quebec Declaration":1) understanding the value, 2) planning for active management, 3) monitoring the changes, 4) keeping environmental sustainability. 
"Quebec Declaration" pointed out the importance of intangible heritage in four perspectives: 1) rethinking of place, 2) threat of place, 3) safeguarding of place, and 4) transmission of place. Conservation work should focus on both the heritage and its location. A law should be made for limitation, and development plans of conservation are necessary because conservation sometimes involves a wide range of work. In addition, monitoring and knowledge dissemination are both important work to assure that tangible and intangible cultural heritage can be sustainably developed. Therefore, Bureau of Cultural Heritage, now Ministry of Culture of Taiwan, started to host cultural forums for younger generation to raise their awareness and devote themselves in cultural heritage conservation.

\subsection{Scaffolding Learning}

The term of scaffolding is wildly used to describe an efficient learning support (McLoughlin, 2002). Scaffolding is derived from Vygotsky's research about cognitive development of experts and newbie (Vygotsky, 1978). Wood, Burner and Ross developed the theory of scaffolding learning from Vygotsky's theory. This theory indicates that children can carry out tasks which are beyond their ability with the assistance of adults or experienced peers. The concept of scaffolding was derived from the common scaffolding system of architectural engineering. With scaffolds, workers are able to build up constructions from bottom to top. Once the building is constructed, the scaffolds can be removed. Scaffolding is thus defined as a temporary framework (Cazden, 1983).

According Vygotsky's theory, students can develop high-level thinking skills with the "scaffolds" of adult experts or peers of better capacity (Stone \& Wertsch, 1984). Scaffolding learning is a learning process which aims to promote deeper learning. Scaffolding is designed to help students realize their learning goals and provide support especially for students in need in their learning process. The process of using scaffolding includes: model learning, guiding, building scaffolds, removing scaffolds, assessment (Rogoff, 1990). An efficient scaffold have features as follows: 1. Reducing the possibility of failure in the process of learning; 2. Making the learner complete a task which cannot be done by himself; 3.Moving the learner to a new and improved knowledge area; 4 . Guiding the learner to the status of independent capability.

The main purpose of this study is to use the learning activities in youth forums as scaffolds, and to explore students' learning performance and help them develop their cognitive structure of cultural heritage through formal and informal learning activities.

\subsection{Cognitive development}

The common classification of education goals are the following 3 fields: cognitive domain, psychomotor domain and affective domain (Bloom, Enflhar, Furst, Hill, Krathwohl, 1956). From simple to complicated, the cognitive domain is divided into six levels: knowledge, comprehension, application, analysis and synthesis. Mayer and Wittrock think that there are three types of learning: 1) non-learning, 2) rote learning, and 3) meaningful learning. Meaningful learning is to learn in class new knowledge which can be used not only to solve problems, but also to understand new concepts. Therefore, students' cognitive structure in learning new knowledge is the key to meaningful learning. Students who have meaningful learning can get better cognitive results and comprehensive knowledge structure to build more motivation to learn. Mayer and Wittrock divided dimensions of cognitive processes into 6 parts: remember, understand, apply, analyze, evaluate, and create.

This research, according to the cognitive theory mentioned above, analyzes learners' cognitive development and classifies it with remember, understanding, apply, analyze, evaluation, and create to code their assignments to understand learners' learning performance and cognitive development. The research result can help teachers improve their program design to make students have meaningful learning and promote their learning performance. Therefore, this research will explore learners' cognitive development and learning performance according to cognitive theory through learners' interaction in youth forums.

\subsection{Content analysis}

Content analysis is a technique to analyze an object systematically and to quantify the content (Berelson, 1952).Latent content and artificial content can be analyzed and given a series of comment and description by referees with an objective standard or definition (Fearing, 1953). Content analysis is an observation method which is an alternative way to observe or interview people directly, so researchers can use the research data already produced by the objects (Kerlinger, 1964). Content analysis is a systematic and objective stage to process data and the communication produced by objects can be transformed, summarized and compared (Paisley, 1969).

In brief, content analysis is a research method which can convert quality data into quantified data. It has been wildly developed with communication research and analysis since 1930. In the beginning, content analysis is used to analyze newspaper content. With the progress of research method and statistic software, content analysis is widely used in other social science fields. Berelson (1952) pointed out that $90 \%$ of content analysis researches' reliability was between 66\% 95\%. Kassarjian once applied content analysis in customer research; he believed the $85 \%$ reliability was acceptable (Kassarjian, 1977).

Content analysis reliability stands for the consistency among coders, and the reliability is proportional to the consistency. Consistency is the ratio among coders when they analyze the same material with the same standard. There are two ways to calculate the ratio. One is the ratio between agreements over total judgements. The other is to combine all the judgements from all coders (Kassarjian, 1977). Mutual reliability method was conducted in this study. (Wang, 1992). The calculating procedures is shown as below:

(1). mutual consistency reliability (pi):

$$
p i=\frac{2 M}{\left(N_{1}+N_{2}\right)}
$$

where $\quad \mathrm{M}=$ Quantity assessed by both coders which have the same result

N1, N2=Quantity assessed by each coder

(2). average value of mutual consistency $(p)$ :

$$
p=\frac{\sum_{i=1}^{n} p i}{N}
$$

where $\quad N=$ The total number of coders assess for each other (3). consistency(r):

$$
r=\frac{n p}{1+[(n-1) p]}
$$


where $\quad n=$ Number of coders

In summary, content analysis is a quantifying method that can convert qualitative data into quantitative data. The researchers can observe data directly without interference. Some researches indicate that the reliability of content analysis method is based on mutual consistency reliability. If the reliability coefficient is higher than $85 \%$, it means the research has credibility. In addition, content analysis is based on the message given by the objects of study, and it is thus away from the impact of respondents. Reliability coefficient will be calculated in this study.

\subsection{Latent Semantic Analysis}

Latent semantic analysis (LSA) is a theory and method to reinterpret articles by looking into words that are related to certain concepts in a statistic way. Then, compare the location and frequency of these words fetched from the original documents to determine the degree of similarity between the two articles (Landauer \& Dumais, 1997).

LSA can calculate not only the frequency of keywords, but also can use singular value decomposition (SVD) to speculate the deeper relation between word and word. The procedure of SVD is: 1) build up an occurrence matrix, 2) converting the value in the occurrence matrix, 3) decomposing the matrix by SVD, 4) using singular value to reconstruct the matrix. Before using SVD, we shall put into a huge amount of articles of relevant fields to train and build SVD space.

Foltz pointed out that there were some ways to use LSA in text research, including matching the abstract and the main body, representing the quality of the article, and measuring the coherence of the text (Foltz, 1996). He also showed that LAS can analyze automatically the similarity between documents. The most commonly used method to compare document similarity is to compute the value of the two vectors between $\cos \theta$

Formula 4 showed that the keywords, in the teaching materials provided by teachers, are represented as vectors. If there are $\mathrm{N}$ keywords, and the time every keyword appears is fi, we can get the vector.

$$
F=\left(f_{1}, f_{2}, f_{3}, \ldots, f_{\mathrm{n}}\right)
$$

Formula 5 showed that if there are $\mathrm{N}$ keywords in every student's feedback and the time every keyword appears is fk.

$$
G=\left(g_{1}, g_{2}, g_{3}, \ldots, g_{\mathrm{k}}\right)
$$

Formula 6 showed how to calculate the similarity between teaching materials and students' feedback.

$$
\cos \theta=\frac{\mathrm{F} \cdot \mathrm{G}}{|\mathrm{F}||G|}
$$

In summary, LSA is a kind of statistical method and theory that can re-interpret those concept words extracted from articles. LSA can determine the similarity between two articles through position and frequency of keywords that appear in articles.

Singular value decomposition can be further analyze deeper relations between words. However, we do not use SVD conversion when we only need to compare the similarity between teaching materials and students' feedback.

In this study, because of the lack of a proper Chinese teaching material for establishing required research SVD space, the study merely focused on the similarity between the "Quebec Declaration" and students' feedback.

\subsection{Summary}

The main purpose of this study is to explore the learning performance of students of different backgrounds and their' cognitive development about culture properties by analyzing their assignments through content analysis method. Participants were 80 students who had attended the 2009 youth forum held in the southern Taiwan.

Both quality and quantity methods were conducted in this study. The hypotheses of this research were as follows:

H1-1: Students of different school systems have significant difference in cognitive development about assets conservation.

H1-2: Students of different learning fields have significant difference in cognitive development about assets conservation.

\section{METHOND}

\subsection{Participants}

Participants were 80 university students who participated in the cultural youth forum held on November, 7, 2010.

\subsection{Youth forum activities}

Participants were from learning fields about cultural property and were recommended by their teachers. If the number of participants was less than expected, the forum would be open to students of other learning fields. There were both lecture courses and field survey activities. The main teaching material was "Quebec Declaration." Five places for field survey were selected. After the youth forum, participants had to hand in their 1,000 words feedback which would be the sources for analysis.

\subsection{Research methods}

This study uses "content analysis," "latent semantic analysis," and "independent-sample $t$ test" to verify the results.

\subsubsection{Content analysis}

The researchers invited three graduate students to use content analysis to collate the students' feedback and to calculate mutual reliability in order to understand the cognitive development of the participants. After the analysis, each feedback was given a score according to the result to provide for the subsequent statistical analysis.

\subsubsection{Latent semantic analysis method}

The study used quantitative method to analyze the students' feedback which was pre-processed by CKIP system. Then LSA method was conducted to compare the similarity between each feedback and "Quebec Declaration". The results were used as basic data for subsequent statistical analysis. 


\subsubsection{Independent-sample T test}

Independent-sample $\mathrm{T}$ test is applied to explore if there is any significant difference between dependent variables of two nominal independent variables. This study did difference analyses which used both content analysis result and LSA analysis result to see if there is significance between students of different backgrounds.

\subsection{Data collection}

First, content analysis was conducted in in this study to classify students' feedback according to cognitive process categories revised by Anderson et al. In order to avoid inconsistence in encoding standard due to the time-consuming and overmuch encoding, this study slightly adjusted the procedure by shortening the time of coding to ensure that the coding procedure would be finished within a day. Before coding, the researcher read and marked the relevant paragraphs, so coders could concentrate on those paragraphs and get rid of the unrelated text. Once the coding was completed, the researcher calculated the reliability coefficient and checked if it matched the standard of credibility. Each feedback was scored from 3 to 18 points by the 3 coders.

Independent-sample $\mathrm{T}$ test was conducted to verify the hypotheses.

Second, CKIP system was applied on "Quebec Declaration" to build the keyword vector F. Then, each student's feedback was analyzed with CKIP system to build the keyword vector Gn. Cosine $\theta$ was calculated on the basis of article cosine similarity formula. Finally, independent-sample $\mathrm{T}$ test was conducted to verify the hypotheses.

\section{EXPERIMENTAL ANALYSIS}

\subsection{Sample}

The samples of this research are the participants of the Youth Forum of 2009. Every student's background was classified according to the Ministry of Education department name and department code.

Based on the classification of school system, there were 38 undergraduate students $(47.5 \%)$ and 42 graduate students $(52.5 \%)$. According to the classification of learning field, there were 37 students major in art and humanity (46.25\%), 1 in social science $(0.01 \%), 41$ in manufacturing and construction $(51.25 \%)$, and 1 in service $(0.01 \%)$. Samples of social science and service were ignore because both learning fields had only 1 participant and small number of participant was not useful as comparison groups and had little inference value.

\subsection{Reliability of content analysis}

There were 3 coders participated in this study. After the content analysis, the reliability was .857 which agreed with Kassarjian's claim (Table 1).

Table 1. Mutual reliability

\begin{tabular}{ccc}
\hline Coder & Coder A & Coder B \\
\hline Coder B & .688 & \\
\hline Coder C & .638 & .675 \\
\hline
\end{tabular}

Reliability $=\frac{3 \times(.688+.638+.675) / 3}{1+[(3-1) \times(.688+.638+.675) / 3]}=.857$

\subsection{Result of assets conservation and cognitive development}

After an afternoon of coding, the result of three coders in accordance with six classifications of the cognitive development process is shown as Table 5. Row 1 shows the number of coding results which the three coders had same opinions: remember 1 , understand 16, apply and analyse 0 , evaluate 1 , and creation 1 . Row 2 shows the number of coding results that coder A agreed with coder B: remember 4, understand 9, apply and analyse 0 , evaluate 1 , creation 0 and so on (Table 2 ).

Table 2. Coding result of students' feedback

\begin{tabular}{cccccccc}
\hline NO & Coder Result & $\mathrm{R}$ & $\mathrm{U}$ & $\mathrm{Ap}$ & $\mathrm{An}$ & $\mathrm{E}$ & $\mathrm{C}$ \\
\hline 1 & $\begin{array}{c}\text { All Coders have } \\
\text { same opinion }\end{array}$ & 1 & 16 & 0 & 0 & 1 & 1 \\
\hline 2 & $\begin{array}{c}\text { Coder A agree with } \\
\text { Coder B }\end{array}$ & 4 & 9 & 0 & 0 & 1 & 0 \\
\hline 3 & $\begin{array}{c}\text { Coder A agree with } \\
\text { Coder C }\end{array}$ & 1 & 11 & 0 & 2 & 2 & 3 \\
\hline 4 & $\begin{array}{c}\text { Coder B agree with } \\
\text { Coder C }\end{array}$ & 1 & 13 & 0 & 0 & 1 & 1 \\
\hline 5 & Only Coder A & 5 & 6 & 0 & 3 & 9 & 5 \\
\hline 6 & Only Coder B & 13 & 6 & 2 & 1 & 1 & 7 \\
\hline 7 & Only Coder C & 1 & 5 & 0 & 11 & 3 & 5 \\
\hline
\end{tabular}

Note: R: remember, U: understand, Ap: apply, An: analyse, E: evaluate, C: create.

The information above is presented in a bar graph below. The coding result reveals that most of the students' cognitive development was focused on understanding stage, followed by remember stage. Few students went up to evaluation and creation stage.

However, the main activity of this youth forum was visiting a tile factory, instead of learning skills from skilled workers. Therefore, there was nearly no student whose cognitive development touched on application stage (Figure 1).

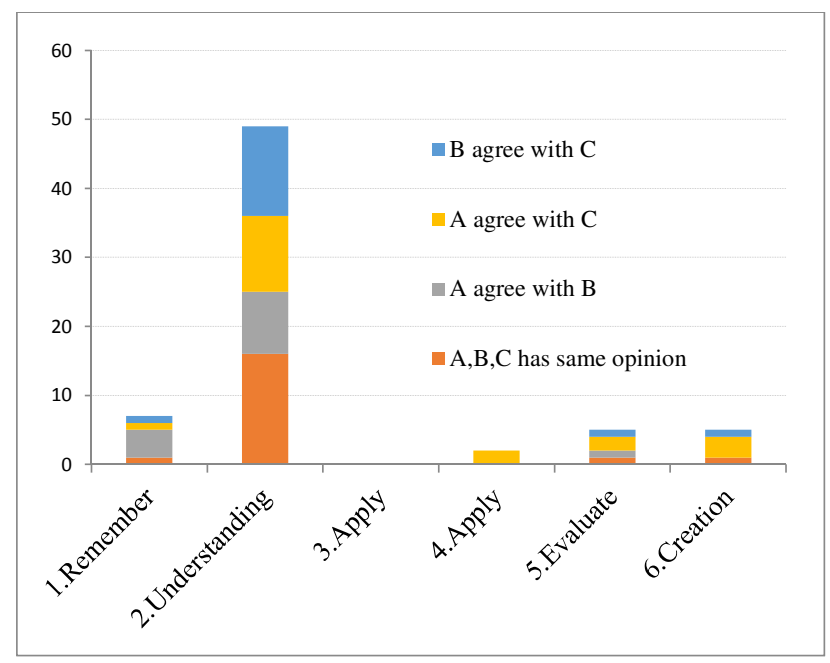

Figure 1. Bar chart of students' cognitive development by content analysis

Shapiro-Wilk normality test was conducted for scores converted from the result of content analysis. In regards to school system, the results show that the statistic of the undergraduate is .840 , 
while that of the graduate is .946 . The corresponding significance value of both results is smaller than .05; that shows the scores converted from the result of content analysis is not a normal distribution. When it comes to learning field, the results show that the statistic of art and humanity is .897 and manufacturing and construction is .937. The corresponding significance value of both is smaller than .05 ; that shows the scores converted from the result of content analysis is not a normal distribution (Table 3).

Table 3. Normality test of scores converted from content analysis

\begin{tabular}{ccccccc}
\hline \multirow{2}{*}{ variables } & \multicolumn{3}{c}{ Kolmogorov-Smirnov test ${ }^{\mathrm{a}}$} & \multicolumn{3}{c}{ Shapiro-Wilk normality test } \\
\cline { 2 - 8 } & statistic & $\mathrm{df}$ & $\mathrm{sig}$ & statistic & $\mathrm{df}$ & sig \\
\hline undergraduate & .274 & 34 & .000 & .840 & 34 & .000 \\
\cline { 2 - 7 } graduate & .145 & 43 & .024 & .946 & 43 & .044 \\
\hline $\begin{array}{c}\text { Art and Humanity } \\
\text { Manufacturing and } \\
\text { construction }\end{array}$ & .223 & 38 & .000 & .897 & 38 & .002 \\
\cline { 2 - 7 } & .176 & 39 & .004 & .937 & 39 & .030 \\
\hline
\end{tabular}

\subsection{CKIP system}

"Quebec Declaration" was analyzed by CKIP system. Those single-letter words and words that only appeared once were excluded. The top three most frequent words are:1) place (47 times), 2) spirit (42 times), 3) intangible (16 times), (Table 4).

Table 4 Frequency of keywords in "Quebec Declaration" analyzed by CKIP

\begin{tabular}{|c|c|}
\hline Frequencies & Term \\
\hline 2 (times) & $\begin{array}{l}\text { following, whole, multiple, specific, because, } \\
\text { so, that is, oral, special, must, further, } \\
\text { compare, compare, population, human, } \\
\text { generation, life, community, science, paper, } \\
\text { flavor, expert, affective, education, groups, } \\
\text { organization, concept, authorities, process, } \\
\text { dimension, festival, conflict, discipline } \\
\text { charter, multimedia, architecture, conference, } \\
\text { database, participants, global, field, website, } \\
\text { Canada, past, other, for, through, interaction, } \\
\text { play, join, bring, spread, develop, } \\
\text { dissemination, communication, prevent } \\
\text { announce, description, encourage, closely, } \\
\text { extensive, change, rich, globalization, share, } \\
\text { included, somewhat, receive, agree, adapt, } \\
\text { get, needs }\end{array}$ \\
\hline 3 (times) & $\begin{array}{l}\text { common, diversity, digital, not only, } \\
\text { document, way, method, component, suggest, } \\
\text { technology, principle, Characteristic, feature, } \\
\text { dynamic, country, entity, ceremony, forum, } \\
\text { local, legislation, change, protection, } \\
\text { provide, consideration, ensure, sustainable, } \\
\text { important, special, promote, continue }\end{array}$ \\
\hline 4 (times) & $\begin{array}{l}\text { element, annual meeting, role, object, } \\
\text { knowledge, threat, policy, context, habit, } \\
\text { landscape, route, Quebec, same time, all, } \\
\text { give, suggest, relevant }\end{array}$ \\
\hline 5 (times) & $\begin{array}{l}\text { since, government, memory, management, } \\
\text { world, these, they, pass, transfer }\end{array}$ \\
\hline 6 (times) & Plan, site, meaning, monuments, difference \\
\hline 7 (times) & development, traditional, understand \\
\hline 8 (times) & and, group, value, guard, tangible \\
\hline $\begin{array}{c}\text { Over } 10 \\
\text { (times) }\end{array}$ & $\begin{array}{l}\text { declaration ( } 10 \text { times), conservation ( } 13 \\
\text { times), culture (14 times), society (14 times), } \\
\text { we ( } 14 \text { times), heritage ( } 15 \text { times), intangible }\end{array}$ \\
\hline
\end{tabular}

(16 times), spirit (42 times), place (47 times)

\subsection{Results of Latent Semantic Analysis}

After checking the bar chart, one outlier (S04) which is 3 times more than standard value was found and deleted according to Shiffler suggestion. Most content of the outlier were copied from "Quebec Declaration" and had almost no feedback about it. After deleting the outlier, 77 students' feedback was left for further analyzing.

Shapiro-Wilk normality test was conducted for LSA $\cos \theta$. From school system perspective, the results show that the statistic of the undergraduate is .971 , while that of the graduate is .986. The corresponding significance value of both is more than .05. It indicates that the LSA $\cos \theta$ is not a normal distribution. From learning field perspective, the results show that the statistic of art and humanity is .976 and manufacturing and construction is .978 . The corresponding significance value of both is more than .05. It also shows that the LSA $\cos \theta$ is not a normal distribution (Table 5)

Table 5 LSA $\operatorname{COS} \theta$ Normality test

\begin{tabular}{|c|c|c|c|c|c|c|c|}
\hline & \multirow{2}{*}{ variables } & \multicolumn{3}{|c|}{ Kolmogorov-Smirnov test ${ }^{\mathrm{a}}$} & \multicolumn{3}{|c|}{ Shapiro-Wilk Normality test } \\
\hline & & statistic & df & sig & statistic & df & sig \\
\hline \multirow{4}{*}{$\begin{array}{c}\text { LSA } \\
\cos \theta\end{array}$} & \multirow{2}{*}{$\begin{array}{l}\text { undergraduate } \\
\text { graduate }\end{array}$} & .097 & 34 & $.200^{*}$ & .971 & 34 & .501 \\
\hline & & .079 & 43 & $.200^{*}$ & .986 & 43 & .874 \\
\hline & \multirow{2}{*}{$\begin{array}{c}\text { Art and humanity } \\
\text { Manufacturing and } \\
\text { construction }\end{array}$} & .100 & 38 & $.200^{*}$ & .976 & 38 & .589 \\
\hline & & .099 & 39 & $.200^{*}$ & .978 & 39 & .639 \\
\hline
\end{tabular}

a. Lilliefors Significant correction

*. Lower limit of true significantly

\subsection{Result of content analysis}

\subsubsection{Independent-sample T test}

This study invited 3 coders to classify each students' feedback. Each feedback was given a score ranging from 1 to 6 . For example, remember- 1 point, understand- 2 points, apply- 3 points, analysis- 4 points, evaluation- 5 points, and creation- 6 points. All the scores evaluated by 3 coders were summed up, so each feedback had a score ranging from 3 to 18 . The larger value represented cognitive development.

After independent-sample $\mathrm{T}$ test, analysis from the school system construct revealed that the score of the undergraduate $(M=7.11, S D=2.82)$ is higher than that of the graduate $(M=$ 7.86, $S D=2.77$ ). Analysis from the learning fields construct revealed that score of arts and humanities fields $(M=8.05, S D=$ $3.05)$ is less than that of manufacturing and construction fields $(M=7.03, S D=2.47)$ (Table 6).

Table 6. Independent-sample t test of content analysis

\begin{tabular}{cccccccc}
\hline & variables & $\mathrm{N}$ & Avg. & SD & $t$ & Hypnosis \\
\hline \multirow{2}{*}{$\begin{array}{c}\text { School } \\
\text { system }\end{array}$} & undergraduate & 35 & 7.11 & 2.82 & & H1-1 \\
\cline { 2 - 5 } & graduate & 43 & 7.86 & 2.77 & & Not established \\
\hline \multirow{2}{*}{$\begin{array}{c}\text { Learning } \\
\text { fields }\end{array}$} & $\begin{array}{c}\text { Art and } \\
\text { humanity }\end{array}$ & 38 & 8.05 & 3.05 & & \\
\cline { 2 - 5 } & $\begin{array}{c}\text { Manufacturing } \\
\text { and } \\
\text { construction }\end{array}$ & 40 & 7.03 & 2.47 & & Not established \\
\hline Note: $N=78$ & & & & & & \\
\hline
\end{tabular}


4.6.2 Hypothesis testing

1. H1-1: Students from different school systems show no significant difference in cognitive development about assets conservation.

An independent-samples t-test was conducted to compare the condition of the undergraduate and the graduate. There is no significant difference in the scores of the undergraduate $(M=$ 7.11, $S D=2.82)$ and those of the graduate $(M=7.86, S D=2.77)$; $t(78)=-1.176, p=.243$. These results suggest that there is no significance difference between the undergraduate students' feedback and the graduate students' feedback. H1-1 hypothesis is thus not established (Table 6).

2. H1-2: Students from different learning fields show no significant difference in cognitive development about assets conservation.

An independent-samples t-test was conducted to compare the condition of the undergraduate and the graduate. There was no significant difference in the scores of art and humanity $(M=$ $8.05, S D=3.05)$ and those of manufacturing and construction $(M=7.03, S D=2.47) ; t(78)=1.632, p=.107$. These results show that there is no significance difference between art and humanity students' feedback and manufacturing and construction students' feedback. H1-2 hypothesis is thus not established (Table 6).

\subsection{Result of latent semantic analysis}

This study uses LSA to calculate the similarity between students' feedback and "Quebec Declaration". The value of similarity is from 0 to 1 . The larger value indicates higher similarity.

After independent-sample T test, analysis of the school system construct shows that the score of the undergraduate $(M=.319$, $S D=.055)$ is higher than that of the graduate $(M=.316$, $S D=.054)$. Analysis of the learning fields construct shows that the score of arts and humanities fields $(M=.313, S D=.054)$ is less than that of manufacturing and construction fields $(M=.321$, $S D=.064)$ (Table 7).

Table 7. Independent-sample t test of LSA

\begin{tabular}{|c|c|c|c|c|c|c|}
\hline & variables & $\mathrm{N}$ & Avg. & SD & $t$ & Hypnosis \\
\hline \multirow{2}{*}{$\begin{array}{l}\text { School } \\
\text { system }\end{array}$} & undergraduate & 34 & .319 & .055 & \multirow{2}{*}{.202} & \multirow{2}{*}{$\begin{array}{c}\text { H1-1 } \\
\text { Not established }\end{array}$} \\
\hline & graduate & 43 & .316 & .063 & & \\
\hline \multirow{2}{*}{$\begin{array}{l}\text { Learning } \\
\text { fields }\end{array}$} & $\begin{array}{c}\text { Art and } \\
\text { humanity }\end{array}$ & 38 & .313 & .054 & \multirow{2}{*}{$\begin{array}{c}- \\
.597\end{array}$} & \multirow{2}{*}{$\begin{array}{c}\text { H1-2 } \\
\text { Not established }\end{array}$} \\
\hline & $\begin{array}{l}\text { Manufacturing } \\
\text { and construction }\end{array}$ & 39 & .321 & .064 & & \\
\hline
\end{tabular}

1. H1-1: Students from different school systems show no significant difference in cognitive development about assets conservation.

An independent-samples t-test was conducted to compare LSA $\cos \theta$ of undergraduate and graduate conditions. There is no significant difference in the scores of the undergraduate $(M=$ $3.19, S D=.55)$ and those of graduate $(M=.316, S D=.063)$; $t(77)=.202, p=.313$. These results suggest that there is no significance difference between the undergraduate students' feedback and the graduate students' feedback. H1-1 hypothesis is thus not established (Table 7).
2. H1-2: Students from different learning fields show no significant difference in cognitive development about assets conservation.

An independent-samples t-test was conducted to compare LSA $\cos \theta$ of undergraduate and graduate conditions. There is no significant difference in the scores of art and humanity $(M=.313, S D=.054)$ and those of manufacturing and construction $(M=.321, S D=.064) ; t(77)=-.597, p=.349$. These results show that there is no significance difference between art and humanity students' feedback and manufacturing and construction students' feedback. H1-2 hypothesis is thus not established (Table 7).

\subsection{Summary}

The results show that all the participants from different school systems and learning fields have no significant difference. It shows that the students of unrelated fields could bring some ideas different from the cultural heritage fields' students. For example:

(S30): People need more practice to tell stories to foreign friends about something interesting such as traditional architectural components, the origin of decoration, etc. Compared to guidebooks and websites, independent travellers can have deeper and more personal experiences. If we do love our cultural heritages and are willing to devote ourselves to the conservation of culture, we can start writing personal blogs in different languages to introduce our cultural heritages. I believe that the information will get more attention from people all over the world through the limitless Internet. There is plenty of information on the Internet; however, people usually lose the opportunity to learn things about different cultures because of the barrier of language. If we can translate the information about our culture into other languages, more people may be able to know about our culture, and we are thus connected to the world.

(S44): I hope that the forum can be opento people or experts of different fields to extend the variety of ideas and make more people aware of the issues about conservation.

Paris Declarations points out that stakeholders should be trained professionally to raise their awareness of heritage conservation. In the future, the stakeholders will also have the right to comment the process of development, and that will break the present status: the task of heritage conservation always falls on experts.

In addition, through Shapiro-Wilk test, the results show that there no significant difference between students from different school systems and different learning fields. In Shapiro-Wilk LSA cosine test, the result also shows no significant difference.

\section{CONCLUSION}

\subsection{Conclusion}

This research aims to discuss how to use youth form as a scaffold to assist students in their cognitive development about cultural heritage. Content analysis and LSA method was conducted to analyze the learning performance of students of different backgrounds. Participants were 80 students who attended youth forum in 2009. The results are as below:

1. Scaffolding is helpful for participants' cognitive development of cultural heritage 
The formal and informal interactive learning in Youth Forum activities helped students establish the concept of asset preservation. The results show that students have achieved stage of memory and understanding. A few students achieved stage of evaluation and creating. It means that the participants have achieved a considerable amount of learning in cognitive development about assets conservation.

2. There is no significant difference in cognitive development between the students of different backgrounds after the youth forum

Both qualitative and quantitative methods were conducted in this study to analyze the feedback given bythe participants. The results show that there is no significant difference between the cognitive development of students of different backgrounds. Judged from the curriculum planning, the forum was particularly designed for students who major in architecture in order to make them think more and deeper about conservation. However, the responsibility of assets conservation falls on all stakeholders.

3. The analysis result of LSA is better than the result of content analysis

In this study, we found that LSA method gets better results than content analysis because the result of LSA shows a normal distribution. In addition, through computerized analysis, LSA can effectively reduce the human factors of research bias. Therefore this study recommends that future studies use LSA method in order to achieve better research results.

\subsection{Suggestion}

1. Open youth forum to participants of different backgrounds to collect different points of view.

2. Set up definite educational objectives to facilitate the design and implementation of follow-up courses.

3. Establish the mechanism of filtering participants of youth forums and select appropriate students to improve the interaction.

\section{REFERENCES}

Academia Sinica Institute of Information Science Thesaurus Team (CKIP)(2007) • retrieved October 29, 2012, from http://ckipsvr.iis.sinica.edu.tw/ 。

Berelson, B. (1952). Content analysis in communication research. Retrieved from http://psycnet.apa.org/psycinfo/195307730-000

Bloom, B. S., Englhart, M. D., Furst. E. J., Hill, W. H., \& Krathwohl, D. R.(1956). Taxonomy of Educational Objectives. Handbook I: Cognitive Domain. New York: McKay.

Bureau of Cultural Heritage. retrieved October 29, 2012, from http://www.boch.gov.tw/boch/frontsite/cms/newsDetailViewAct ion.do?method=doViewNewsDetail\& contentId=4966\&isAddHi tRate $=$ true $\&$ relation $\mathrm{Pk}=4966 \&$ tableName $=$ content $\&$ iscancel $=\mathrm{tr}$ ue \&menuId $=3401$

Cazden, C. (1983). Adult assistance to language development: Scaffolds, models, and direct instruction. Developing literacy: Young children's use of language, 3-18.
Fearing, F. (1953). Toward a psychological theory of human communication. Journal of Personality, 22(1), 71-88.

Foltz, P. W. (1996). Latent semantic analysis for text-based research. Behavior Research Methods, 28(2), 197-202.

Kassarjian, H. H. (1977). Content analysis in consumer research. Journal of consumer research, 8-18.

Kerlinger, F. N. (1964). Foundations of Behavioral Research. Educational and Psychological Inquiry, New York: Holt, Rinehart and Winston. Inc.

Landauer, T. K., \& Dumais, S. T. (1997). A solution to Plato's problem: The latent semantic analysis theory of acquisition, induction, and representation of knowledge. Psychological Review; Psychological Review, 104(2), 211.

Mayer, R. E., \& Wittrock, M. C. (2001). The revised taxonomy structure: The cognitive process dimension. In L. W. Anderson, D. R. Krathwohl, P. W. Airasian, K. A. Cruikshank, R. E. Mayer, P. R. Pintrich, J. Raths, \& M. C. Wittrock (Eds.), A taxonomy for learning, teaching, and assessing: A revision of Bloom's taxonomy of educational objectives(pp. 63-92). New York: Addison Wesley Longman, Inc.

McLoughlin, C. (2002). Learner support in distance and networked learning environments: Ten dimensions for successful design. Distance Education, 23(2), 149-162.

Norberg-Schulz, C. (2002). Genius Loci (Shih Jiih Ming, Trans).Taipei: Garden, 18. (Original work published1980)

Paisley, W. J. (1969). Studying style as deviation from encoding norms. The analysis of communication content, 133-146.

Rogoff, B. (1990). Apprenticeship in thinking: Cognitive development in social context. Oxford University Press. Retrieved from http://doi.apa.org/psycinfo/1990-97332-000

Shiffler, R. E. (1988). Maximum $\mathrm{Z}$ score and outliers. The American Statistician, 42(1),79-80.

Stone, C. A., \& Wertsch, J. V. (1984). A social interactional analysis of learning disabilities remediation. Journal of Learning Disabilities, 17(4), 194-199.

Vygotsky, L. (1978). Mind in society: The development of higher psychological processes. Cambridge, MA: Harvard University Press. (Original material published in 1930, 1933 and 1935).

Wang Tan Fan(1992). Communication and content analysis. Taipei: Babylion. 